\title{
Evidence that chemical signals promote fighting between intact male hooded rats
}

\author{
BARRY FASS, J. RUSSELL MASON, and DAVID A. STEVENS \\ Clark University, Worcester, Massachusetts 01610
}

\begin{abstract}
Male members of mixed-sex colonies of hooded rats were exposed to three types of same-age conspecific intruders: intact male (M), castrated male (C), and ovariectomized female (OVX). During the first $20 \mathrm{~min}$ after intruder introduction, colony males sniffed the anogenital region of $\mathrm{C}$ or OVX intruders more frequently and for longer durations than they sniffed that of $\mathbf{M}$ intruders. Twenty-one hours later, fewer $\mathrm{C}$ and $\mathrm{OVX}$ intruders had suffered wounds than $\mathrm{M}$ counterparts, and their wound scores were lower. OVX intruders were not rendered more susceptible to attack by painting their anogenital region with fresh $M$ urine. These findings have implications for Adams' model of intermale fighting, and they indicate that onset of attack by male hooded rats is promoted by testosterone-related anogenital substance(s).
\end{abstract}

Chemical signals are important for promoting onset of intraspecific fighting behaviors of several rodent species (Fass \& Stevens, 1977; Lee, 1976). Male mice and hamsters, for example, evidently possess a urinary substance that renders them susceptible to attacks by male conspecifics. Urine-painting experiments demonstrated that application of unfamiliar male conspecific's urine to the fur of castrated intruders resulted in frequent attacks by territory-occupying male conspecifics (Mackintosh \& Grant, 1966; Mugford \& Nowell, 1970; Payne, 1974). By contrast, castrated intruders that were untreated or treated with water rarely elicited attack (Lee \& Brake, 1971, 1972; Payne, 1974).

Onset of fighting between male rats conceivably is promoted by chemical signals also. Adams (1976; Lehman \& Adams, 1977) proposed that a resident male rat exhibits offensive behavior after making an olfactory comparison between a familiar environment and an unfamiliar male conspecific intruder. This proposal is supported by several findings. Male rats scent mark their home region with urine (Richards \& Stevens, 1974), they discriminate between familiar and unfamiliar urines of male conspecifics (Fass, Gutermann, \& Stevens, 1978; Krames \& Shaw, 1973), and resident males alternate between sniffing their home environment and the anogenital region of an unfamiliar male conspecific intruder before they attack (Adams, 1976; Lehman \& Adams, 1977). The hypothesis that male rats' urine is a vehicle for attack-promoting substance(s) remains to be tested, however.

Address reprint requests to Barry Fass, who is now at the Department of Neurosurgery, Box 420, University of Virginia School of Medicine, Charlottesville, Virginia 22908. J. Russell Mason is now at Monell Chemical Senses Center, 3500 Market Street, Philadelphia, Pennsylvania 19104. The authors thank D. B. Adams, R. J. O'Connell, and N. S. Thompson for their helpful suggestions.
Territory-occupying male rats do not attack conspecific intruders indiscriminately. Male intruders are attacked very frequently, whereas castrated or ovariectomized intruders are attacked infrequently if at all (Thor \& Flannelly, 1976). One might predict, based upon Adams' (1976) model, that resident males use chemical cues to discriminate among intruders of different hormonal status. The present investigation was conducted to assess this prediction and to determine whether male rats' urine is a vehicle for attackpromoting substance(s).

\section{EXPERIMENT 1: COLONY MALES VS. UNPAINTED INTRUDERS}

This study is similar to one performed by Thor and Flannelly (1976) that dealt with intruder gonadectomy and elicitation of attacks by colony male rats. Thor and Flannelly used colony males that were older and almost twice as heavy as conspecific intruders, however, and their findings may have been due to size differences rather than to chemical signals. The present investigation involved use of like-aged colony and intruder rats, in order to control age-related differences in body weight and size that might promote attack (Payne \& Swanson, 1970; Slob \& van der Werff ten Bosch, 1975).

\footnotetext{
Method

Subjects. Fifty-four sexually naive rats of the Charles River Long-Evans strain were used. Eighteen were intact males, 12 were intact females, 12 were castrated males, and 12 were ovariectomized females. Gonadectomies were performed (at Charles River Breeding Laboratories) when the subjects were 26 days old.

Procedure. Each rat was housed individually from 30 to 150 days of age in a wire-mesh cage $(18 \times 25 \times 20 \mathrm{~cm})$ with a reversed 12-h light-dark cycle and food and water available ad lib. Six intact males, selected randomly, were designated as colony members; they were kept in a room separate from that in which the other rats were housed. At 150 days of age, each colony male was transferred to a larger wire-mesh cage $(28 \mathrm{x}$
} 
$28 \times 34 \mathrm{~cm}$ ) and housed with two intact females for 2 weeks prior to the start of testing. The remaining 12 intact males (M), 12 castrated males (C), and 12 ovariectomized females (OVX) were designated as intruders. They were housed individually throughout the experiment.

When all subjects were about 165 days old, intruders were introduced into colony cages on 6 alternate days. Every colony male was exposed to six intruders, two from each intruder group, one per day. Every intruder was exposed to only one colony male, and the order of intruder-colony pairings was counterbalanced completely.

Colony females were removed from colony cages about $1 \mathrm{~h}$ prior to intruder introduction and returned immediately after each test period. A $25-\mathrm{W}$ red incandescent bulb provided illumination during testing, which began several hours after onset of darkness.

Electromechanical counters were used to record frequencies of the following behaviors exhibited by colony males or intruders during the first $20 \mathrm{~min}$ after intruder introduction: (1) sniff anogenital region, (2) nosing, (3) attack (and latency to first attack), (4) full aggressive groom, and (5) mount (described by Grant \& Mackintosh, 1963).

Intruders were removed from colony cages $21 \mathrm{~h}$ after introduction. Each intruder was asphyxiated with ether, shaved, and then the numbers of small (less than $.5 \mathrm{~cm}$ ), medium (between .5 and $1.0 \mathrm{~cm}$ ), and large (greater than $1.0 \mathrm{~cm}$ ) wounds were counted. A wound score was calculated for each intruder (after Luciano \& Lore, 1975).

\section{Results and Discussion}

Fighting behavior rarely occurred during the 20-min observation period. Only 6 of 36 colony male/intruder pairs fought; four fights involved $M$ intruders and two involved $\mathrm{C}$ intruders. There were no intergroup differences on most of the behavioral measures (e.g., attack, full aggressive posture, offensive side posture, full submissive posture, mount). However, Table 1 shows that colony males did respond differently to the three intruder groups. Colony males sniffed the anogenital regions of $\mathrm{C}$ and OVX intruders more often and for longer durations than those of $\mathrm{M}$ intruders, but the colony males nosed $M$ intruders more frequently than they nosed OVX intruders.

Although fighting occurred infrequently during the 20-min observation periods, it occurred very often during the ensuing 20-h interval, as shown by wound scores. The proportion of $M$ intruders that suffered wounds was greater than the corresponding proportions of $\mathrm{C}$ and OVX intruders (confirmed by Fisher exact probability tests, $\mathrm{p}<.05)$. Almost all $(92 \%) \mathrm{M}$ intruders were wounded, whereas only $41 \%$ and $17 \%$ of $\mathrm{C}$ and OVX intruders sustained wounds. In summary, then, $M$ intruders were sniffed least frequently, but they were nosed and wounded most frequently.

\section{EXPERIMENT 2: COLONY MALES VS. URINE-PAINTED INTRUDERS}

\section{Method}

Subjects. Sixty sexually naive Long-Evans hooded rats were used. Eighteen were intact males, 12 were intact females, and 30 were ovariectomized females. Ovariectomies were performed (at Charles River Breeding Labs) when the rats were 26 days old. Housing conditions were similar to those of Experiment 1.

Procedure. Six males were selected randomly and designated as colony members. At 150 days of age (i.e., after 120 days of individual housing), each colony male was transferred to a large cage and housed with two intact females for 2 weeks prior to the start of testing. Six other males (M) and six ovariectomized females (OVX) were selected randomly and designated as urine donors. These 12 rats were housed individually in a different room from the one in which colony males were maintained. The remaining six males served as "confrontation" rats for urine donors during urine-collection periods (see below). The remaining 24 ovariectomized females were designated as intruders; half were treated with $\mathrm{M}$ urine just prior to testing, and the others were treated with OVX urine.

When all intruders were approximately 165 days old, they were introduced into colony cages on 4 alternate days. Every colony male was exposed to four intruders, two painted with $M$ urine (experimental intruder group) and two with OVX urine (control intruder group). Every intruder was exposed to only one colony male, according to the method of Experiment 1.

Urine samples were collected by placing individual donors in metabolism cages (similar to their home cages) at the beginning of the dark cycle. During each 12-h collection period, donors' metabolism cages were abutted by the home cages of "confrontation" males in an attempt to simulate conditions under which rats might produce and excrete attack-promoting urine. A urine mixture for each donor group was prepared by combining 3-cc urine samples from each donor. $\mathrm{M}$ and $\mathrm{OVX}$ urine mixtures were stored in a refrigerator for the 12 -h period prior to application onto intruders' fur, so that urine mixtures would be fresh when used. One cubic centimeter of either urine mixture was applied to the anogenital region of each intruder immediately before introduction into a colony cage. Experimenters wore plastic gloves when painting urine on intruders to avoid contaminating the samples.

\section{Results}

OVX intruders painted with $M$ urine were not attacked or wounded more frequently than were their counterparts painted with OVX urine. Colony males attacked only $16 \%$ of intruders with $M$ urine and $16 \%$ with OVX urine during the initial $20 \mathrm{~min}$ after intruder introduc-

Table 1

Experiment 1: Colony Males vs. Unpainted Intruders

\begin{tabular}{|c|c|c|c|c|c|c|c|c|c|}
\hline \multirow{2}{*}{$\begin{array}{l}\text { Intruder } \\
\text { Group }\end{array}$} & \multirow[b]{2}{*}{$\mathrm{PI}_{\mathbf{w}}$} & \multicolumn{2}{|c|}{ Wound Scores } & \multicolumn{2}{|c|}{ Nosings } & \multicolumn{2}{|c|}{$\begin{array}{c}\text { Number of Times Sniffed } \\
\text { by Colony Male }\end{array}$} & \multicolumn{2}{|c|}{$\begin{array}{l}\text { Duration of Sniffing } \\
\text { by Colony Male* }\end{array}$} \\
\hline & & Mean & SE & Mean & $\mathrm{SE}$ & Mean & SE & Mean & SE \\
\hline M & $11 / 12$ & $37.70^{\mathbf{a}}$ & 13.10 & $4.75^{a}$ & .69 & $17.5^{\mathrm{a}}$ & 3.03 & $.57^{\mathrm{a}}$ & .14 \\
\hline $\mathrm{C}$ & $5 / 12$ & $1.75^{\mathrm{b}}$ & 1.53 & $3.50^{\mathrm{a}, \mathrm{b}}$ & .91 & $25.6^{\mathrm{b}}$ & 2.70 & $1.98^{\mathrm{b}}$ & .41 \\
\hline ovx & $2 / 12$ & $3.17^{b}$ & 3.08 & $2.33^{\mathrm{b}}$ & .55 & $28.4^{b}$ & 4.36 & $1.55^{\mathrm{b}}$ & .31 \\
\hline
\end{tabular}

Note-For each column, only differences between group means with different superscripts are statistically significant $(p<.05$, MannWhitney $U$ test). $P I_{w}=$ proportion of intruders with wounds. $\quad{ }^{*}$ In minutes. 
tion. Thirty-three percent of intruders with $\mathbf{M}$ urine sustained wounds over a $21 \mathrm{~h}$ period, whereas none of the intruders with OVX urine was wounded. There were no significant differences between the two intruder groups on any of the behavioral measures.

\section{DISCUSSION}

A testosterone-related urinary odorant is thought to elicit attack behavior by male mice and hamsters (e.g., Evans \& Brain, 1978). Evidence for the existence of a urinary attackpromoting odorant was provided by urine-painting experiments (Mackintosh \& Grant, 1966; Payne, 1974). A urine-painting paradigm was used in the present investigation in a preliminary attempt to ascertain whether male hooded rats also possess urinary attack-promoting substance(s). Results of Experiment 1 indicate that attack susceptibility of male hooded rats is promoted by testosterone-related substance(s). The data of Experiment 2 are more difficult to interpret conclusively, but they suggest that urine of male hooded rats (unlike that of male mice or hamsters) is not a vehicle for attack-promoting substance(s).

$M$ intruders of Experiment 1 were sniffed less frequently and wounded more severely by colony males than were gonadectomized intruders. This finding confirms previously reported ones (Fass, Gutermann, \& Stevens, 1979; Thor \& Flannelly, 1976). Attack susceptibility is thought to be testosterone related (Flannelly \& Thor, 1978; Thor \& Flannelly, 1976). Testosterone might enhance attack susceptibility in three ways: (1) by stimulating development of attack-eliciting bodily features (such as size or weight), (2) by increasing the occurrence of attack-eliciting behaviors (Lee \& Crump, 1980), and/or (3) by promoting secretion of attack-eliciting substance(s). The results of Experiment 1 do not support the first two possibilities. Colony males and $M$ intruders were approximately the same age, so that there were no obvious differences between their physical dimensions. The three intruder groups did not differ from each other on any of the behavioral measures, indicating that behavioral differences probably do not account for the results. Consequently, a more likely possibility is that $\mathrm{M}$ intruders possess testosterone-related attack-promoting substance(s).

Adams (1976) proposed that territory-occupying male rats make an olfactory comparison between their home environment and an unfamiliar conspecific intruder. Conceivably, unfamiliar intruders with high testosterone levels release aversive anogenital substance(s) and are attacked, whereas intruders with low levels release attractive substance(s) (or no substance) and are not attacked. There is considerable evidence that such substances exist and are contained in urine (e.g., Krames, Carr, \& Bergman, 1969). On the basis of Adams' model of intermale fighting, we predicted that urine of $\mathrm{M}$ rats is a vehicle for attackpromoting substance(s). However, the results of Experiment 2 do not confirm this prediction. One plausible interpretation of these results (aside from methodological considerations) is that anogenital sebaceous gland secretion(s) (rather than urine) serve(s) as vehicle. A test of this interpretation is warranted because of its potential implications for Adams' model of intermale fighting and for understanding how chemical signals control offensive behavior.

\section{REFERENCES}

ADAms, D. B. Relation of scent-marking, olfactory investigation, and specific postures in isolation-induced fighting of rats. Behaviour, 1976, 56, 286-298.
Evans, C. M., \& Brain, P. F. Effects of age at castration on testosterone induced aggression-promoting cues in groups of male mice. Physiology \& Behavior, 1978, 21, 19-23.

Fass, B., Gutermann, P. E., \& Stevens, D. A. Evidence that rats discriminate between familiar and unfamiliar putative urinary odorants of adult male conspecifics. Aggressive Behavior, 1978, 4, 231-236.

Fass, B., Gutermann, P. E., \& Stevens, D. A. Evidence that resident male albino rats are not immune to attacks by conspecific intruders. Aggressive Behavior, 1979, 5, 135-141.

Fass, B., \& Stevens, D. A. Pheromonal influences on rodent agonistic behavior. In D. Muller-Schwarze \& M. M. Mozell (Eds.), Chemical signals in vertebrates. New York: Plenum, 1977.

Flanelly, K. J., \& Thor, D. H. Territorial aggression in the rat: Elicitation by intruders castrated at one, ten, thirty, and sixty days of age. Physiology \& Behavior, 1978, 20, 785-789.

Grant, E. C., \& Mackintosh, J. H. A comparison of the social postures of some common laboratory rodents. Behaviour, 1963, 21, 246-259.

Krames, L., Carr, W. J., \& Bergman, B. A pheromone associated with social dominance among male rats. Psychonomic Science, 1969, 16, 11-12.

Krames, L., \& Shaw, B. Role of previous experience in the male rat's reaction to odors from group and alien conspecifics. Journal of Comparative and Physiological Psychology, 1973, 82, 442-448.

LEE, C. T. Agonistic behavior, sexual attraction, and olfaction in mice. In R. L. Doty (Ed.), Mammalian olfaction, reproductive processes, and behavior. New York: Academic Press, 1976

LEE, C. T., \& BrAKe, S. C. Reactions of male fighters to male and female mice, untreated or deodorized. Psychonomic Science, 1971, 24, 209-211.

LeE, C. T., \& Brake, S. C. Reaction of male mouse fighters to male castrates treated with testosterone proprionate or oil. Psychonomic Science, 1972, 27, 287-288.

LEE, C. T., \& CRUMP, M. A possible confound and the role of olfaction in mouse aggressive interactions. Aggressive Behavior, 1980, 6, 131-138.

Lehman, M. N., \& Adams, D. B. A statistical and motivational analysis of the social behaviours of the male laboratory rat. Behaviour, 1977, 61, 238-275.

Luciano, D., \& Lore, R. Aggression and social experience in domesticated rats. Journal of Comparative and Physiological Psychology, 1975, 88, 917-923.

Mackintosh, J. H., \& Grant, E. C. The effect of olfactory stimuli on the agonistic behavior of laboratory mice. Zeitschrift für Tierpsychologie, 1966, 23, 584-587.

Mugford, R. A., \& Nowell, N. W. Pheromones and their effect on aggression in mice. Nature, 1970, 226, 967-968.

Payne, A. P. The effects of urine on aggressive responses by male golden hamsters. Aggressive Behavior, 1974, 1, 71-79.

Payne, A. P., \& Swanson, H. H. Agonistic behaviour between pairs of hamsters of the same and opposite sex in a neutral observation area. Behaviour, 1970, 36, 259-269.

Richards, D. B., \& STevens, D. A. Evidence for marking with urine by rats. Behavioral Biology, 1974, 12, 517-523.

SLOB, A. K., \& VAN DE R WerfF TEn Bosch, J. J. Sex differences in body growth in the rat. Physiology \& Behavior, 1975, 14, 353-362.

ThoR, D. H., \& Flannelly, K. J. Intruder gonadectomy and elicitation of territorial aggression in the rat. Physiology \& Behavior, 1976, 17, 725-727.

(Received for publication January 20, 1981.) 